\title{
SIMPLE ULTRASHORT LIGHT PULSE CHIRP MEASUREMENT DEVICE*
}

\author{
V. Kabelka \\ Institute of Physics, Savanoriu 231, LT-02300 Vilnius, Lithuania \\ E-mail: vidask@ktl.mii.lt
}

Received 10 October 2005

\begin{abstract}
A simple device, Frequency Tracer (FT), for simultaneous measurement of ultrashort light pulse duration and chirp is presented. FT operation is based on the two-dimensional image analysis (time versus frequency) of the non-colinear secondharmonic autocorrelator beam, and FT enables one to evaluate the temporal phase variation over the femtosecond pulse duration. The spectral information of a fs pulse in FT originates from the angular divergence of a second-harmonic signal beam, and there is no need to use the spectral apparatus. Femtosecond pulses duration and chirp measurements of the Ti:sapphire laser system multi-pass amplifier (MPA) during adjustment of the compressor pair of gratings were made.
\end{abstract}

Keywords: ultrafast pulses, ultrafast measurements, nonlinear optics, temporal phase, optical device, correlators

PACS: 42.65.Re

\section{Introduction}

Ultrashort light pulse characterization, which in general includes determination of the temporal dependence of the instantaneous frequency (chirp) or, equivalently, spectral phase, is a difficult and complicated task [113]. Our previous theoretical analysis has shown that the well-known nonlinear autocorrelator based on noncolinear second-harmonic generation (SHG) [13], in addition to pulse duration measurements, can provide measurements of the chirp of a fs pulse $[2,4,13]$. The SHG autocorrelation method has been verified experimentally with femtosecond pulses produced by the Ti:sapphire laser system based on the Colliding Pulse Amplification (CPA) scheme [7].

\section{Theory}

In this work we present a Frequency Tracer (FT) as a simple device for the ultrashort pulse duration and temporal phase measurement (Fig. 1(a,b)). The FT can work in two regimes: autocorrelator (AC) mode and FT mode. In AC mode the initial fs pulse light beam has to be divided into two beams, and the pulses in these beams are directed to the second-harmonic crystal to produce the second harmonic beam by the mechanism

\footnotetext{
* The report presented at the 36th Lithuanian National Physics Conference, 16-18 June 2005, Vilnius, Lithuania.
}

of sum-frequency generation. The width of the secondharmonic beam $\Delta x$ is proportional to the pulse duration $\tau$, provided the beam diameter $d$ is large enough [2]:

$$
d>\Delta x=\frac{c \tau}{2 \sin (\varphi / 2)} A
$$

where $c$ is the speed of light, $\varphi$ is the angle between two beams of the initial pulse. The dimensionless factor $A$ takes into account the increase of the autocorrelation function as compared to the initial function.

In FT mode the Frequency Tracer is designed to analyze the wavefront curvature of the second-harmonic beam which is proportional to the fs pulse chirp. To resolve the wavefront curvature of the second-harmonic beam the slit-diaphragm $\mathrm{D}$ and cylindrical lens CL are used (Fig. 1(a)). In the horizontal plane of setup the spherical lens SL displays the divergence of the second-harmonic beam in the charge coupled device (CCD) horizontal registration area, while in the vertical plane cylindrical and spherical lenses $\mathrm{CL}$ and SL project the autocorrelation function to the CCD. This means that the second-harmonic beam produced in the autocorrelator is converted by the optical setup into a two-dimensional image where the vertical coordinate $y$ stands for time $t$ and the horizontal one $x$ - 


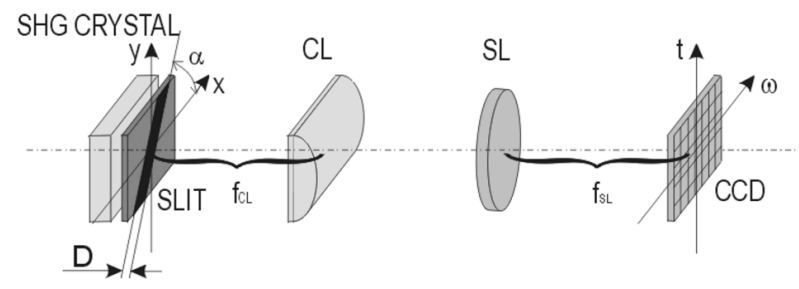

(a)

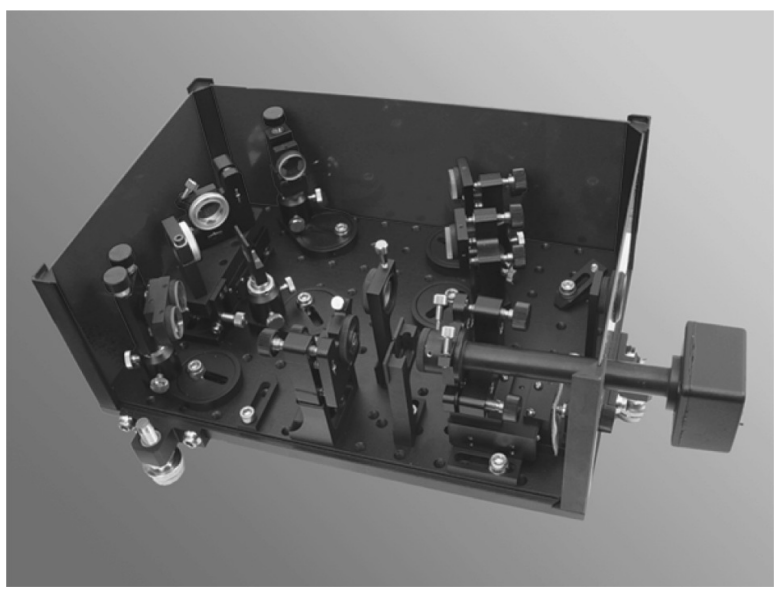

(b)

Fig. 1. (a) Design of optical setup of FT. SHG crystal is second harmonic generation crystal, D is slit-diaphragm, CL is cylindrical lens, $\mathrm{SL}$ is spherical lens, $f_{\mathrm{CL}}$ is focal length of cylindrical lens, $f_{\mathrm{SL}}$ is focal length of spherical lens, CCD is charge coupled device, $\alpha$ is the angle of slit-diaphragm orientation. (b) Photo of FT device.

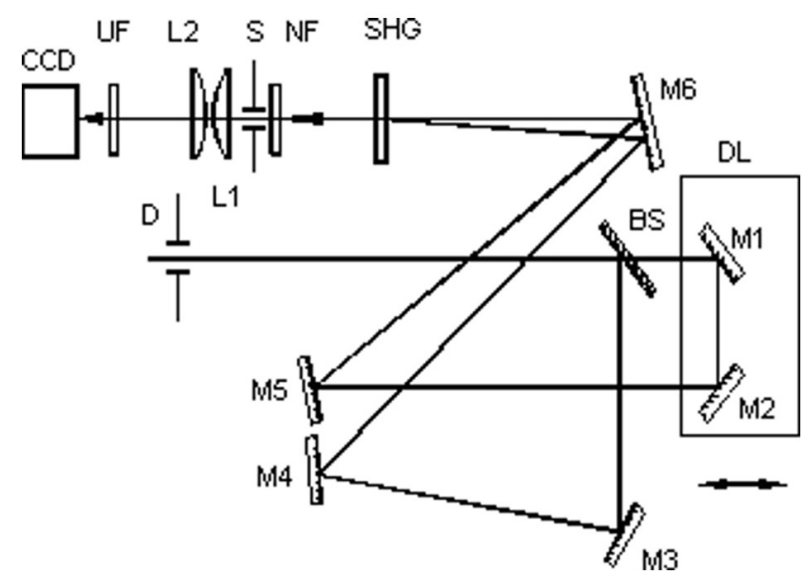

Fig. 2. Experimental setup of FT.

for instantaneous frequency $\Omega$. The following relations give the scales [4]:

$$
t=\frac{y f_{\mathrm{CL}}}{c f_{\mathrm{SL}}} \frac{\sin (\varphi / 2)}{\tan \alpha}, \quad \Omega=\frac{x \omega_{0}}{f_{\mathrm{SL}}} \frac{1}{\sin (\varphi / 2)},
$$

where $\alpha$ is the angle of slit-diaphragm orientation, $\omega_{0}$ is the central frequency of a fs pulse, $f_{\mathrm{CL}}$ is the focal length of cylindrical lens, $f_{\mathrm{SL}}$ is the focal length of spherical lens.

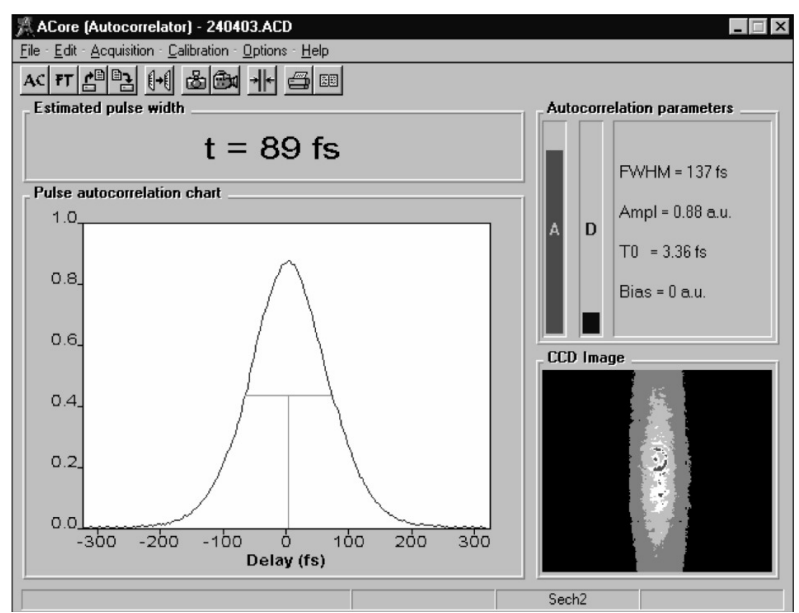

(a)

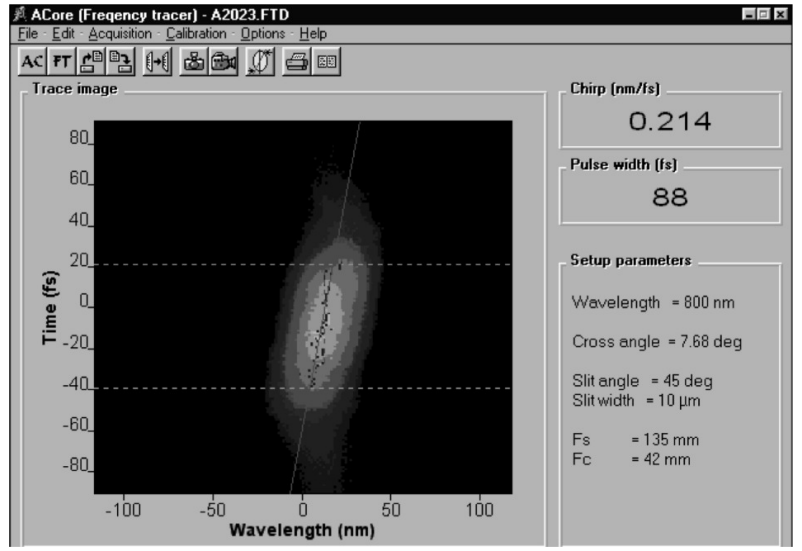

(b)

Fig. 3. (a) AC mode measurements of Ti:sapphire laser system fs pulse FWHM. (b) FT mode measurements of Ti:sapphire laser system fs light pulse instantaneous frequency (chirp) temporal dependence.

\section{Experiment}

The FT device was used to characterize the fs pulses produced by a Ti:sapphire laser system multi-pass amplifier (MPA). The FT input pulse has $P=120 \mathrm{~mW}$, is as short as $40 \mathrm{fs}$, with the $1.66 \mathrm{kHz}$ repetition rate of the 8-pass amplifier compressor (pair of gratings, 800 lines $/ \mathrm{mm}$ ) at $800 \mathrm{~nm}$. The pulse to be measured is directed to the beam splitter BS (50/50\%) through the input diaphragm D (Fig. 2). The transmitted part of a pulse is delayed in the delay line DL using mirrors M1 and M2 and then directed to the secondharmonic generation crystal SHG by mirrors M5 and M6. The second part of a pulse (reflected from the beam splitter) is directed to the second-harmonic crystal by mirrors M3, M4, and M6. Two different crystals phase-matched for the non-colinear SHG were used in the experiment: $1 \mathrm{~mm}$ thick BBO and $300 \mu \mathrm{m}$ KDP. The second-harmonic beam passes neutral filters NF, 


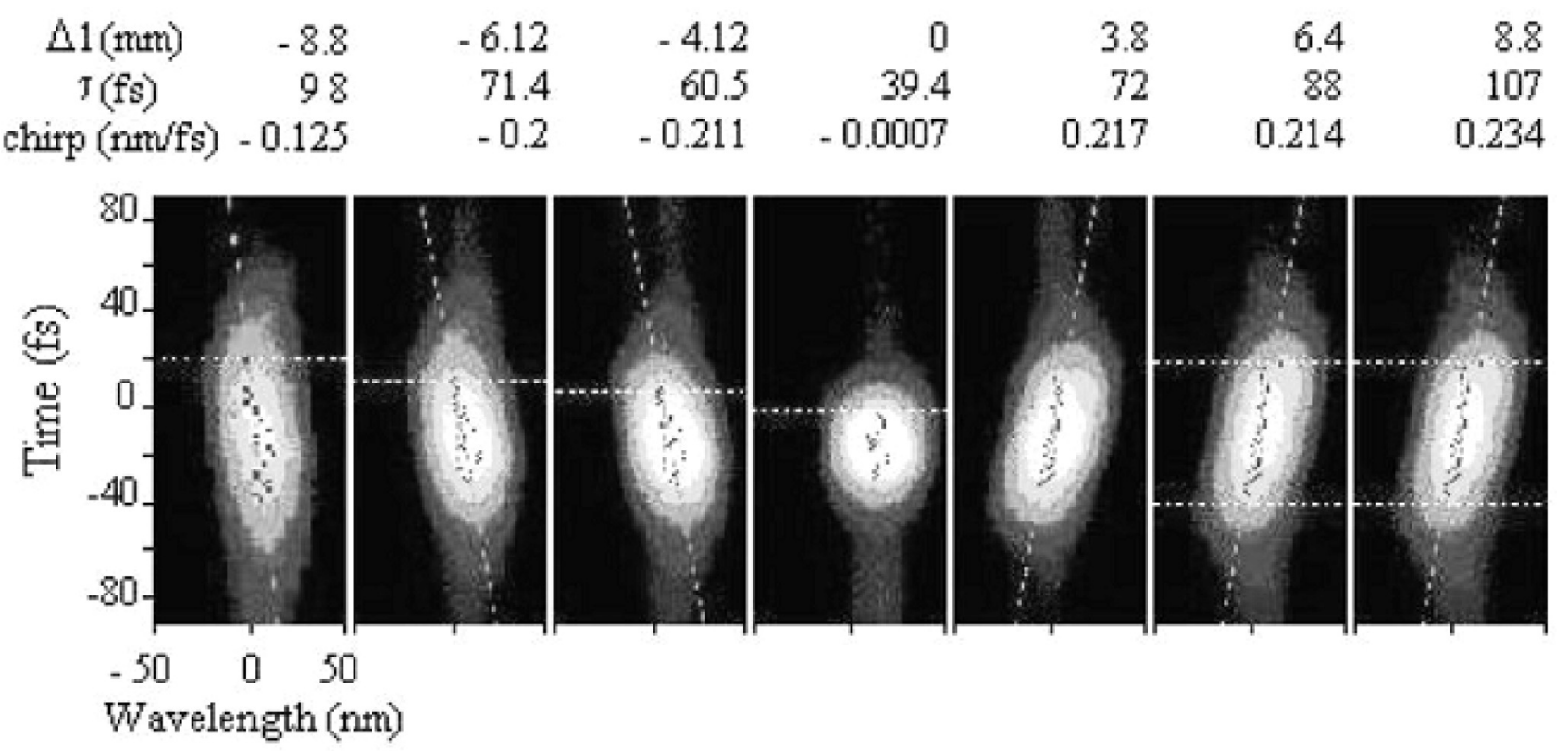

Fig. 4. FT mode visual images at the output of the multipass amplifier.

slit-diaphragm $\mathrm{S}$ (orientation angle $\alpha=45^{\circ}$, width $70 \mu \mathrm{m})$ and is projected to the CCD plane by cylindrical $\left(f_{\mathrm{CL}}=40 \mathrm{~mm}\right)$ and spherical $\left(f_{\mathrm{SL}}=132 \mathrm{~mm}\right)$ lenses; CCD sensitive elements are covered with a UV filter to cut initial pulses. The frequency versus time images were registered with the CCD (EDC-1000, $192 \times 164$ pixel, ELECTRIM Corp.) and transferred by a special interface board to the computer. The data acquired by the computer were processed by the original ACORE program (Avesta Project Ltd), which displays the pulse duration measurement using FWHW autocorrelation function (AC mode) or chirp versus time (FT mode) images on the computer display (Fig. 3(a,b)). Thus, observing the FT image one can estimate the pulse duration, chirp (and its sign), and temporal dependence of instantaneous frequency. This image reproduced by the CCD camera looks like a ridge and has simple intuitive meaning (Fig. 4): the maximum brightness at fixed time indicates the instantaneous frequency $\Omega$ of a pulse. The measurements have shown that the chirp and pulse duration reaches the minimal values at $0 \mathrm{~mm}$ adjustment point of the multi-pass amplifier compressor pair of gratings. The FT device does not require complicated mathematical calculation to estimate pulse characteristics. Nevertheless, accurate data on the chirp and pulse duration can easily be extracted from the image by using scaling formulas and well-known relation between the autocorrelation width and the pulse duration. In our work [7] the values of the linear chirp have been extracted from these images plotted against grating separation, and for each image the autocorrelator function has been calculated as an integral of the image intensity over the "frequency" coordinate.

\section{Conclusions}

The optical device, Frequency Tracer, which visualizes and quantifies the chirp of a single femtosecond light pulse is designed and manufactured. FT can work in single-shot and multi-pulse regimes. FT directly visualizes the chirp and its sign over the fs pulse duration as the two-dimensional image without any retrieval mathematical algorithm for creating the additional theoretical retrieved image. The main advantages of the FT are: simplicity of optical layout - no spectrometer, small amount of optical elements, operation in real time, direct mathematical calculation of measured results. As experiments have shown, FT is a robust and easy to use tool for adjustment of fs lasers and amplifiers. FT measures unambiguously, which allows determining the direction of time axis. The Ti:sapphire MPA laser system fs pulses have been experimentally characterized using the FT.

\section{Acknowledgements}

The author is very grateful to Dr. A.V. Masalov, Dr. A.V. Konyashchenko, Dr. V.S. Pazyuk of Lebedev Physical Institute, Moscow, Russia for their helpful cooperation and to the Lithuanian State Science and Studies Foundation for supporting the project MATILDA. 


\section{References}

[1] A. Brun, P. Georges, G. Le Saux, and F. Salin, Singleshot characterization of ultrashort light pulses, J. Phys. D: Appl. Phys. 24, 1225-1233 (1991).

[2] V. Kabelka and A.V. Masalov, Determination of spectral width and chirp of ultrashort light pulses by analysis of second-harmonic beam divergence, Opt. Commun. 100, 482-486 (1993).

[3] J. Paye, M. Ramaswamy, J.G. Fujimoto, and E.P. Ippen, Measurement of the amplitude and phase of ultrashort light pulses from spectrally resolved autocorrelation, Opt. Lett. 18, 1946-1948 (1993).

[4] V. Kabelka and A.V. Masalov, Angularly resolved autocorrelation for single-shot time-frequency imaging of ultrashort light pulse, Opt. Commun. 121, 141-148 (1995).

[5] R. Trebino, K.W. DeLong, N. Fittinhoff, J. Sweetser, M.A. Krumbügel, B.A. Richman, and D.J. Kane, Measuring ultrashort laser pulses in the time-frequency domain using frequency-resolved optical gating, Rev. Sci. Instrum. 68, 3277-3295 (1997).

[6] C. Iaconis and I.A. Walmsley, Spectral phase interferometry for direct electric-field reconstruction of ultrashort optical pulses, Opt. Lett. 23, 792-794 (1998).

[7] V. Kabelka, A.V. Masalov, S. Nikitin, and H. Milchberg, Tracing the phase distortion of a single ultrashort light pulse from angularly resolved second-harmonic autocorrelator, Opt. Commun. 156, 43-48 (1998).

[8] A. Baltuška, M.S. Pshenichnikov, and D.A. Wiersma, Second-harmonic generation frequency-resolved optical gating in the single-cycle regime, IEEE J. Quant. Electron. 35, 459-478 (1999).

[9] C. Dorrer, B. de Beauvoir, C. Le Blanc, S. Ranc, J.P. Rousseau, J.P. Chamberet, and F. Salin, Singleshot real-time characterization of chirped-pulse amplification systems by spectral phase interferometry for direct electric-field reconstruction, Opt. Lett. 24, 1644-1646 (1999).

[10] L. Gallmann, D.H. Sutter, N. Matuschek, G. Steinmeyer, and U. Keller, Techniques for the characterization of sub-10-fs optical pulses: A comparison, Appl. Phys. B 70, Suppplement, S67-S75 (2000).

[11] P. O'Shea, M. Kimmel, X. Gu, and R. Trebino, Highly simplified ultrashort pulse measurement, Opt. Lett. 26, 932-934 (2001).

[12] V. Kabelka and A.V. Masalov, Method and device for one or more ultrashort light pulses duration and phase characteristics measurement, Patent of the Republic of Lithuania, No LT 5203 B, 2005.

[13] J. Jansky, G. Gorradi, and R.N. Gyuzalian, On possibility of analyzing the temporal characteristics of short light pulses, Opt. Commun. 23, 239-242 (1977).

\title{
PAPRASTAS ULTRATRUMPŲJŲ ŠVIESOS IMPULSŲ TRUKMĖS IR FAZINIŲ CHARAKTERISTIKŲ MATAVIMO IRENGINYS
}

\author{
V. Kabelka \\ Fizikos institutas, Vilnius, Lietuva
}

\section{Santrauka}

Pasiūlytas ir eksperimentiškai išbandytas ultratrumpụjų šviesos impulsų trukmès ir faziniu charakteristiku matavimo būdas ir įrenginys, pagristas nekolinearios antros harmonikos spinduliuotès generavimu. Siūlomas būdas ir ịrenginys pasižymi paprastumu: fazinių charakteristikų registravimui nereikalingas spektrinis prietaisas ir laikinès fazės iškraipymai šviesos impulso trukmejje yra tiesiogiai nustatomi iš vieno lazerio spinduliuotès blyksnio, nenaudojant sudètingo matematinio apdorojimo. Matavimų metu laikinès fazès iškraipymai yra tiesiogiai susieti su laikine koordinate (nèra matavimų neapibrèžtumo), kas leidžia nustatyti laiko ašies kryptị impulso atžvilgiu. 